\title{
Challenges of stroke management in resource-limited settings: A case-based reflection
}

\author{
Yohane G. Gadama ${ }^{1}$, Gloria Mwangalika ${ }^{2}$, Louis B. Kinley ${ }^{3}$, Beth Jackson ${ }^{1}$, \\ Henry C. Mwandumba ${ }^{2,4}$, Jane Mallewa ${ }^{5}$, Tom Solomon ${ }^{6}$, Rob Simister ${ }^{7}$, Laura A. Benjamin ${ }^{6,7}$, \\ Maria I. Vargas ${ }^{8}$, Joseph Kamtchum-Tatuene ${ }^{2,6}$, Tamara Phiri ${ }^{5}$
}

\author{
1. Department of Medicine, Queen Elizabeth Central Hospital, Blantyre, Malawi \\ 2. Malawi-Liverpool-Wellcome Trust Clinical Research Programme, College of Medicine, University of Malawi, Blantyre, Malawi \\ 3. Department of Radiology, Queen Elizabeth Central Hospital, Blantyre, Malawi \\ 4. Department of Clinical Sciences, Liverpool School of Tropical Medicine, Liverpool, United Kingdom \\ 5. Department of Medicine, College of Medicine, University of Malawi, Blantyre, Malawi \\ 6. Liverpool Brain Infections Group, Institute of Infection and Global Health, University of Liverpool, Liverpool, United Kingdom \\ 7. Hyper-acute Stroke Unit, University College Hospital, London, United Kingdom \\ 8. Department of Neuroradiology, Geneva University Hospital, Geneva, Switzerland
}

Correspondence: Dr Joseph Kamtchum-Tatuene (tatuene@liverpool.ac.uk)

\begin{abstract}
A 19-year-old man presented with a 1-year history of headache, generalised body weakness, progressive memory loss, and disorientation. One month prior to admission, there was aggravation of the weakness of the right upper limb, with new-onset difficulty with mastication, speech impairment, apathy, and urinary incontinence. On clinical examination, the patient had a motor aphasia and a rightsided hemiparesis with increased muscle tone and hyperreflexia. A noncontrast computed tomography (CT) scan of the brain revealed large ischaemic strokes extending beyond the classical vascular territories. Cerebrospinal fluid analysis showed a mildly increased protein level. The electrocardiogram revealed an irregular sinus bradycardia. The remainder of the cardiovascular and laboratory workup was unremarkable. Considering a working diagnosis of central nervous system vasculitis, the patient was treated with aspirin, prednisolone, and physiotherapy. However, he died suddenly a few weeks later. Based on this case, we discuss the challenges of stroke management in resource-limited settings, provide practical tips for general practitioners, reflect on the potential avenues for short- and long-term action, and introduce the budding collaboration platform between the University College London, the University of Liverpool, the Queen Elizabeth Central Hospital, and the Malawi-Liverpool-Wellcome Trust Clinical Research Programme.
\end{abstract}

\section{Introduction}

Stroke is the most common cause of disability and the second most common cause of death worldwide, after ischaemic heart diseases. ${ }^{1}$ In Malawi, it is the 6th biggest killer after infectious diseases. ${ }^{2}$ Although more common in the elderly, stroke also affects young adults and recent data suggest an increasing incidence of ischaemic stroke in young adults, with significant adverse socioeconomic consequences. ${ }^{3}$ Furthermore, stroke in young adults (those younger than 45 years of age) is often initially misdiagnosed by inexperienced clinicians because of its unexpectedness, leading to lost opportunities for intervention. ${ }^{4,5}$ In highincome countries, stroke is labelled as cryptogenic in up to one-third of cases. ${ }^{6-8}$ The challenge of appropriate diagnosis and management of stroke is even greater in low-income countries where there is a dearth of basic equipment, trained personnel, and specific drugs. In this paper, through a case managed at Queen Elizabeth Central Hospital (QECH) in Blantyre, we discuss the challenges of stroke management in resource-limited settings, provide practical tips for general practitioners, and reflect on the potential avenues for shortand long-term action.

QECH, which is Malawi's largest referral hospital, does not house a stroke unit; therefore, all stroke cases are managed within the internal medicine department. The hospital has a Magnetic Resonance Imaging (MRI) department, the construction of which was funded by the Blantyre Malaria Project.9 However, computed tomography (CT) is only accessible in Lilongwe, the capital city, which is over 350 $\mathrm{km}$ away. There are in-house radiologists but neurology, neurosonology, and neuroradiology expertise is only provided sporadically by visiting researchers.

\section{Case presentation}

A 19-year-old man presented with a 1-year history of persistent headache of variable intensity, associated with generalised body weakness, progressive memory loss and disorientation, with the patient being unable to find his way back home whenever he went out of the house. One month prior to admission, he experienced an aggravation of the weakness of the right upper limb, with new-onset difficulty with mastication, speech impairment, excessive sleepiness, and urinary incontinence. During the course of his illness, the patient had been hospitalised several times and treated for meningitis, cerebral malaria, and psychosis, without clear evidence for these diagnoses. There was no fever, no seizures, no vomiting, and no visual symptoms. There was no history of hypertension, diabetes mellitus, or consumption of tobacco, alcohol, or drugs.

On clinical examination, the patient was found apathetic with a Glasgow Coma Scale score of 14 (eye opening to verbal command). He had a motor aphasia with right-sided hemiparesis, increased muscle tone and brisk reflexes without clonus or Babinski's sign.

A noncontrast CT scan of the brain revealed multiple large, hypodense lesions, extending beyond the classical vascular territories and involving the lenticular nucleus and the frontal operculum on the right, the insula and the frontal lobe on the left, and both putamina and temporal lobes. The lesions were suggestive of recurrent ischaemic strokes and the one in the left frontal lobe seemed more recent and associated with a mild haemorrhagic transformation (Figure 1). 


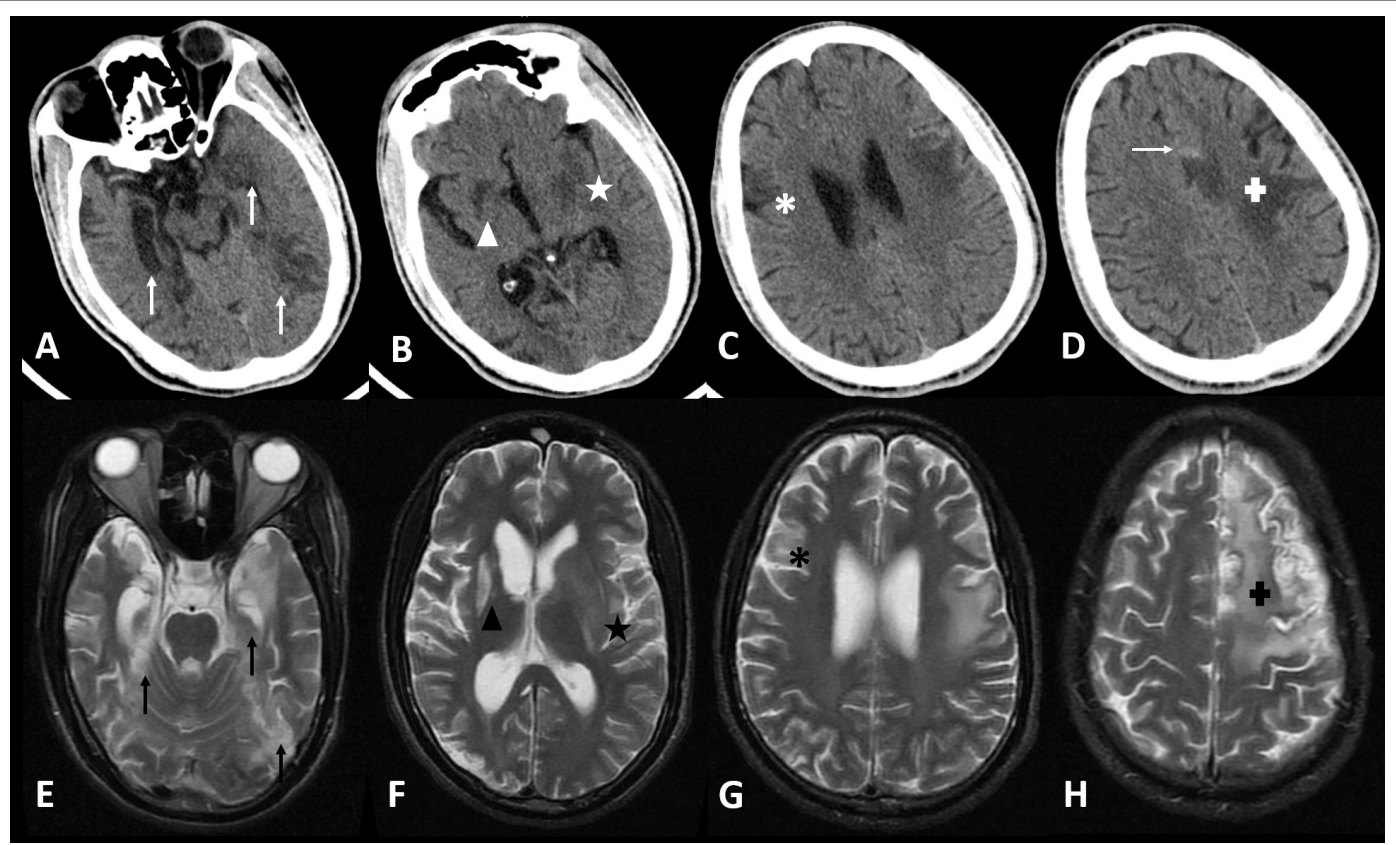

Figure 1: Brain imaging findings

A -D: Axial non-contrast brain CT scan slices showing the ischaemic lesions affecting both temporal lobes (white vertical arrows $-A$ ), the right lenticular nucleus (white triangle $-\mathrm{B}$ ), the left insula and putamen (white star - B), the right frontal operculum (white asterisk -C) and the left frontal lobe (white "plus" sign D). There is a hyperdense dot at the margin of the left frontal infarct, corresponding to a small haemorrhagic transformation (horizontal white arrow - D).

E-H: Axial T2 brain MRI slices showing the ischaemic lesions affecting both temporal lobes (black vertical arrows $-E$ ), the right lenticular nucleus (black triangle $-F$ ), the left insula and putamen (black star $-F$ ), the right frontal operculum (black asterisk - $\mathrm{G}$ ) and the left frontal lobe (black "plus" sign - H).

The full blood count, liver function tests, random blood sugar, and the HIV and syphilis tests were unremarkable. Cerebrospinal fluid analysis revealed a mild increase of the protein level $(0.66 \mathrm{~g} / \mathrm{L}$; normal range: $0.2-0.4)$ but a normal white blood cell count $\left(1 / \mathrm{mm}^{3}\right.$; normal range: $\left.0-5\right)$. The carotid-vertebral ultrasound was unremarkable. The transcranial Doppler could not be performed because there was no temporal window. The electrocardiogram revealed a sinus bradycardia ( 56 beats per minute), with supraventricular extrasystoles. The transthoracic cardiac ultrasound showed a mild dilatation of the right atrium but there was no valvulopathy, myxoma, or intracardiac thrombus. There was no sign of right-to-left shunt, even after microbubble injection at rest (the patient could not perform the Valsalva manoeuvre).

Considering a working diagnosis of recurrent strokes secondary to central nervous system vasculitis, the patient was started on oral low-dose aspirin (75 $\mathrm{mg} /$ day) and prednisolone (60 mg/day). He was also offered some physiotherapy. A noncontrast brain MRI (0.35 T) performed 2 weeks after admission did not show any additional lesions. He was discharged with a schedule for close neurological follow-up. However, the patient's parents reported his sudden death 2 weeks later.

\section{Discussion}

The patient described in this report was diagnosed with recurrent strokes, but the young age, the atypical presentation (chronic headache and alteration of cognitive function, with focal neurological symptoms only appearing at a later stage), the absence of cardiovascular risk factors (diabetes mellitus, hypertension, obesity, smoking, dyslipidaemia), the absence of HIV infection, and the limited accessibility of brain imaging techniques led to recurrent misdiagnosis with ensuing failure to initiate adequate preventive therapy. At first sight, given the distribution of lesions in space (bilateral with cortical involvement) and time (lesions of different ages), one could think of cardioembolism as the primary mechanism of the ischaemic lesions. However, their size, confluence, and extension beyond classical vascular territories speak against this hypothesis and instead suggest either a primary or secondary central nervous system vasculitis, a coagulopathy, or a metabolic or mitochondrial encephalopathy.

Besides the radiological findings, other arguments in favour of a primary central nervous system vasculitis would be the presence of a chronic headache (which is the most common symptom), the insidious progression of disease, the presence of cognitive impairment (which is the second most common symptom), the absence of constitutional symptoms (fever, weight loss, night sweats_as would be seen in systemic vasculitides), and the high protein level in the cerebrospinal fluid. ${ }^{10,11}$ A coagulopathy seems less probable in the absence of past or present thrombotic events in other organs, or episodes of abnormal bleeding-but a definitive conclusion would require a comprehensive assessment of the coagulation profile. The negative family history, the absence of myopathy, and the normal psychomotor development do not support the diagnosis of mitochondrial encephalopathy, but genetic tests would be needed to formally rule out a sporadic case with atypical presentation. Thus, given the limited diagnostic resources, the final cause of the recurrent strokes remains uncertain. The irregular bradycardia found on admission could be related to the lesions of the left insula. Association between insular lesions and arrhythmias have been consistently demonstrated, with left insular lesions most often causing bradycardia. ${ }^{12}$ These perturbations of the cardiac rhythm may explain the patient's sudden death (in the absence of a pacemaker).

This case illustrates a few of the numerous diagnostic and therapeutic challenges related to stroke diagnosis and management in resource-limited settings, as summarised in Table 1. A few practical messages could be formulated for clinicians on the frontline. First, strokes may occur at all ages and should not be considered as only a disease of the 
Table 1a: Diagnostic challenges on the path to better stroke management in low-resource settings

\begin{tabular}{|c|c|}
\hline Challenges & Relevance for this case \\
\hline \multicolumn{2}{|l|}{ Staff } \\
\hline $\begin{array}{l}\text { Improve the availability of neurologists, stroke } \\
\text { physicians and stroke nurses in order to reduce the } \\
\text { frequency of misdiagnoses and poor follow-up. }\end{array}$ & $\begin{array}{l}\text { The diagnosis of stroke could have been made earlier, with } \\
\text { earlier initiation of preventative therapies. }\end{array}$ \\
\hline \multicolumn{2}{|l|}{ Cardiology } \\
\hline $\begin{array}{l}\text { Improve the availability of cardiologist, ECG and } \\
\text { cardiac monitoring device (in-hospital and } \\
\text { ambulatory), and transoesophageal echography. }\end{array}$ & $\begin{array}{l}\text { - Prolonged in-hospital ECG monitoring interpreted by } \\
\text { qualified cardiologists could have helped to identify } \\
\text { transient but more serious dysrhythmias (including } \\
\text { paroxysmal atrial fibrillation). } \\
\text { - Transoesophageal echography is more sensitive than } \\
\text { transthoracic echocardiography for the identification of } \\
\text { patent foramen ovale and intracardiac thrombi. }\end{array}$ \\
\hline
\end{tabular}

\section{Neuroimaging}

Improve the availability of neuroradiologists, high quality brain imaging (Computed Tomography, Subtraction Angiography, and Neurovascular Ultrasound). Magnetic Resonance Angiography, Digital

- A better access to brain imaging might have contributed to reduce the diagnostic delay.

- Vascular imaging (angioCT-scan and contrast-enhanced transcranial Doppler; gadolinium-enhanced T1, 3D TOF, and black-blood MRI sequences) could have highlighted segmental stenosis of large intracranial arteries or areas of contrast enhancement suggesting an ongoing inflammatory process.

\section{Biology and pathology}

Improve the availability of:

- Immunoassays for autoimmune diseases,

- Genetic and biochemical tests for congenital/

inherited or acquired coagulation disorders as well as collagen and mitochondrial diseases,

- CSF serologies and PCR for viral and bacterial pathogens that frequently cause infectious vasculitis, - Equipment for stereotactic biopsy,

- Trained staff for appropriate use of laboratory tests and timely processing of specimens (blood, CSF, urine, biopsies).
Any of these conditions could have been the cause of the recurrent strokes and the availability of appropriate tests would have facilitated the diagnostic discussion.

Table 1b: Therapeutic challenges on the path to better stroke management in low-resource settings

\begin{tabular}{|c|c|}
\hline Challenges & Relevance for this case \\
\hline \multicolumn{2}{|l|}{ Medical } \\
\hline $\begin{array}{l}\text { Improve the availability and diversity of key } \\
\text { therapeutic agents: statins, antihypertensives } \\
\text { (including injectable preparations), oral } \\
\text { antidiabetics, oral/injectable antithrombotic agents } \\
\text { (antiplatelets and anticoagulants with associated tests } \\
\text { for monitoring activity - anti-Xa, INR), recombinant } \\
\text { tissue plasminogen activator, methylprednisolone } \\
\text { and steroid sparing agents for optimal acute and } \\
\text { long-term management of autoimmune vasculitis. }\end{array}$ & $\begin{array}{l}\text { High dose methylprednisolone if frequently used for } \\
\text { treatment initiation in a patient with CNS vasculitis, } \\
\text { followed by long-term immunosuppression by } \\
\text { cyclophosphamide or other steroid-sparing agents. }\end{array}$ \\
\hline $\begin{array}{l}\text { Improve the availability of adequately staffed and } \\
\text { equipped stroke units for optimal monitoring of key } \\
\text { prognostic parameters during the acute phase, better } \\
\text { management of cases and early onset rehabilitation. }\end{array}$ & $\begin{array}{l}\text { This might have improved the outcome in this case, } \\
\text { especially if the diagnosis had been made earlier. }\end{array}$ \\
\hline \multicolumn{2}{|l|}{ Interventional } \\
\hline $\begin{array}{l}\text { Improve the availability of: } \\
\text { - Staff trained for the insertion and surveillance of } \\
\text { pacemakers } \\
\text { - Equipment and trained staff for endovascular } \\
\text { interventions (endarterectomy, stenting, angioplasty) }\end{array}$ & $\begin{array}{l}\text { A pacemaker could have been useful in this patient with } \\
\text { persistent irregular bradycardia and might have prevented } \\
\text { sudden death }\end{array}$ \\
\hline
\end{tabular}

\section{Rehabilitation}

Improve the availability of:

- Neuropsychologists for specific neurocognitive rehabilitation,

There was a clear indication for neuropsychological

- Occupational therapist for optimal organization of post-stroke social and professional reinsertion 
Table 1c: Epidemiologic and public health challenges on the path to better stroke management in low-resource settings

\begin{tabular}{l|l}
\hline Challenges & Relevance for this case \\
\hline $\begin{array}{l}\text { Implementation of proper stroke registers that could } \\
\text { help for real-time monitoring of stroke incidence and } \\
\text { risk factors and inform the planning of public health } \\
\text { interventions. }\end{array}$ & $\begin{array}{l}\text { A better awareness of stroke symptoms could have reduced } \\
\text { the time to consultation, thus allowing earlier diagnosis and } \\
\text { treatment. }\end{array}$ \\
$\begin{array}{ll}\text { Improve population awareness about stroke risk } \\
\text { factors and symptoms and also the necessity to seek } \\
\text { medical advice as soon as possible. }\end{array}$ & \\
\hline
\end{tabular}

Table 2: Clinical clues associated with some common causes of stroke in young adults

\begin{tabular}{|c|c|c|}
\hline \multicolumn{2}{|l|}{ Possible aetiology } & \multirow{2}{*}{$\begin{array}{l}\text { Clinical clues } \\
\text { Neck pain, recent neck trauma or chiropractic manipulation, vigorous } \\
\text { exercise, recurrent cough, lifting up heavy charges or carrying heavy } \\
\text { charges on the shoulders, presence of Claude-Bernard-Horner syndrome } \\
\text { (myosis, ptosis, anhydrosis) }\end{array}$} \\
\hline $\begin{array}{l}\text { Genetic or acquired } \\
\text { arterial diseases } \\
6,7,13,18\end{array}$ & $\begin{array}{l}\text { Cervical artery } \\
\text { dissection }\end{array}$ & \\
\hline & $\begin{array}{l}\text { Noninfectious } \\
\text { vasculitis }\end{array}$ & $\begin{array}{l}\text { Recurrent episodes of skin rashes, joint pains, unexplained fever as seen in } \\
\text { systemic lupus erythematous, weak pulse in Takayasu arteritis }\end{array}$ \\
\hline \multirow[b]{2}{*}{ Cardiac diseases $7,19,20$} & $\begin{array}{l}\text { Patent foramen } \\
\text { ovale }\end{array}$ & $\begin{array}{l}\text { Onset of neurological deficit following Valsalva manoeuvres (push up } \\
\text { exercises, defecation, micturition, lifting up heavy loads), presence of } \\
\text { concurrent deep venous thrombosis }\end{array}$ \\
\hline & $\begin{array}{l}\text { Infectious } \\
\text { endocarditis and } \\
\text { rheumatic heart } \\
\text { diseases }\end{array}$ & Fever, murmur on cardiac auscultation \\
\hline \multirow[b]{2}{*}{ Infections ${ }^{21-26}$} & HIV infection & $\begin{array}{l}\text { HIV infection is a risk factor for stroke and patients should be routinely } \\
\text { tested for the condition, especially when considering the persistently high } \\
\text { prevalence in low-resource settings. }\end{array}$ \\
\hline & $\begin{array}{l}\text { Infectious } \\
\text { vasculitis (VZV, } \\
\text { HSV, } \\
\text { tuberculosis, } \\
\text { syphilis) }\end{array}$ & $\begin{array}{l}\text { Recent episode of zoster (especially ophthalmic zoster), chickenpox, herpes } \\
\text { rash, or tuberculous meningitis. } \\
\text { Recurrent episodes of sexually transmitted diseases and reported risky } \\
\text { sexual behaviours }\end{array}$ \\
\hline \multirow{2}{*}{ Coagulopathies $^{27-29}$} & $\begin{array}{l}\text { Sickle cell } \\
\text { disease }\end{array}$ & Personal and family history, chronic anaemia \\
\hline & Haemophilia & Recurrent episodes of prolonged bleeding \\
\hline \multirow{4}{*}{ Other conditions ${ }^{24,30,31}$} & $\begin{array}{l}\text { Drug and } \\
\text { alcohol abuse }\end{array}$ & $\begin{array}{l}\text { Needle tracks on the skin, perforation of the nasal septum. } \\
\text { Delirium tremens, hypertrophy of parotid glands, macrocytic anaemia and } \\
\text { abnormal liver enzymes }\end{array}$ \\
\hline & Pregnancy & Recent episodes of preeclampsia or eclampsia \\
\hline & $\begin{array}{l}\text { Recent } \\
\text { infections }\end{array}$ & $\begin{array}{l}\text { Flu-like symptoms, gastroenteritis, upper respiratory tract infection in the } \\
14 \text { days preceding stroke onset. }\end{array}$ \\
\hline & $\begin{array}{l}\text { Typical } \\
\text { cardiovascular } \\
\text { risk factors }\end{array}$ & $\begin{array}{l}\text { Hypertension, diabetes mellitus and smoking are possible causes of stroke } \\
\text { in young adults. } \\
\text { The presence of obesity, family history of diabetes, polyuria, polydipsia, } \\
\text { and polyphagia should prompt appropriate screening. }\end{array}$ \\
\hline
\end{tabular}

elderly. In children and young adults, the clinical presentation is often atypical, with chronic headache, seizures, and neurobehavioural symptoms. ${ }^{13}$ Hence, a thorough neurological examination must always be performed to look for discrete signs (for example, speech disturbances, sensory deficits, or abnormal or asymmetric muscle tone or reflexes) suggesting a structural brain lesion, and the threshold for brain imaging should be low. The identification of the aetiology of stroke in young adults is more challenging, because on one hand, classical cardiovascular risk factors are usually absent, and on the other hand, the numerous alternative causes are rare conditions that are difficult to diagnose in low-to-middle income countries. In order to get the best out of the limited resources at their disposal, clinicians should use a stepwise approach, based on epidemiologic data and specific clinical clues (Table 2). Advice should be sought from a physician with expertise in stroke medicine whenever possible, especially for patients with recurrent or cryptogenic strokes.
While waiting for resource and infrastructure improvements, low-to-middle income countries like Malawi can implement some simple solutions to improve stroke care in their local settings. These include raising population awareness about stroke symptoms and risk factors using well-designed communication strategies, ${ }^{14}$ investing in telemedicine for teaching and case management, ${ }^{15,16}$ and strengthening partnerships with high-income countries for the financial, logistic, and training support. There are ongoing discussions between Queen Elizabeth Central Hospital, the MalawiLiverpool-Wellcome Trust Clinical Research Programme, and international partners (University College London Hospitals and the University of Liverpool), in view of initiating a collaborative platform to address some of these challenges in the short term. ${ }^{17}$ The actions implemented will aim to improve clinical care through the creation of a stroke unit, as well as support local stroke research and staff training. 


\section{Acknowledgements}

The authors are grateful to the patient and his parents for granting the permission to use their medical information for teaching and scientific publication.

\section{Competing interests}

All authors declare that they have no competing interests related to this work.

\section{References}

1.WHO. Top 10 causes of death - Fact sheet N³10 Geneva: WHO Press; 2017 [updated January 2017; cited 201704 July ]. Available from: http://www.who.int/entity/mediacentre/factsheets/fs310/en/ index.html\#.

2.Mahawish KM, Heikinheimo T. Stroke in Malawi--what do we know about it and how should we manage it? . Malawi Med J 2010;22(1):2428.

3.Bejot Y, Delpont B, Giroud M. Rising Stroke Incidence in Young Adults: More Epidemiological Evidence, More Questions to $\mathrm{Be}$ Answered. J Am Heart Assoc 2016;5(5).

4.Sultan S, Elkind MS. The growing problem of stroke among young adults. Curr Cardiol Rep 2013;15(12):421.

5.Griffiths D, Sturm J. Epidemiology and etiology of young stroke. Stroke Res Treat 2011;2011:209370.

6.Calvet D. [Ischemic stroke in the young adult]. Rev Med Interne 2016;37(1):19-24.

7.Saver JL. Cryptogenic Stroke. N Engl J Med 2016;375(11):e26.

8.Li L, Yiin GS, Geraghty OC, et al. Incidence, outcome, risk factors, and long-term prognosis of cryptogenic transient ischaemic attack and ischaemic stroke: a population-based study. Lancet Neurol 2015;14(9):903-913.

9.Mwendera CA, de Jager C, Longwe H, Hongoro C, Mutero CM, Phiri KS. Malaria research in Malawi from 1984 to 2016: a literature review and bibliometric analysis. Malar J 2017;16(1):246.

10.Bhattacharyya S, Berkowitz AL. Primary angiitis of the central nervous system: avoiding misdiagnosis and missed diagnosis of a rare disease. Pract Neurol 2016;16(3):195-200.

11.Salvarani C, Brown RD, Jr., Hunder GG. Adult primary central nervous system vasculitis. Lancet 2012;380(9843):767-777.

12.Oppenheimer S. Cerebrogenic cardiac arrhythmias: cortical lateralization and clinical significance. Clin Auton Res 2006;16(1):611.

13.Singhal AB, Biller J, Elkind MS, et al. Recognition and management of stroke in young adults and adolescents. Neurology 2013;81(12):10891097.

14.Nansseu JR, Atangana CP, Petnga SN, Kamtchum-Tatuene J, Noubiap JJ. Assessment of the general public's knowledge of stroke: A cross-sectional study in Yaounde, Cameroon. J Neurol Sci 2017;378:123-129.

15.Bediang G, Perrin C, Ruiz de Castaneda R, et al. The RAFT Telemedicine Network: Lessons Learnt and Perspectives from a Decade of Educational and Clinical Services in Low- and Middle-Incomes Countries. Front Public Health 2014;2:180.
16.Noubiap JJ, Kamtchum-Tatuene J, Nganou-Gnindjio CN, Jingi AM. The Cardio-PadTM project: progress and remaining challenges. Cardiovasc Diagn Ther 2017;7(1):98-101.

17.Benjamin LA. Sharing expertise in stroke in Malawi Liverpool: University of Liverpool; 2017 [updated 11 May 2017; cited 201717 June]. Available from: https://news.liverpool.ac.uk/2017/05/11/sharingexpertise-stroke-malawi/.

18.Duarte MM, Geraldes R, Sousa R, Alarcao J, Costa J. Stroke and Transient Ischemic Attack in Takayasu's Arteritis: A Systematic Review and Meta-analysis. J Stroke Cerebrovasc Dis 2016;25(4):781-791.

19. Morris NA, Matiello M, Lyons JL, Samuels MA. Neurologic complications in infective endocarditis: identification, management, and impact on cardiac surgery. Neurohospitalist 2014;4(4):213-222.

20.Wang D, Liu M, Lin S, et al. Stroke and rheumatic heart disease: a systematic review of observational studies. Clin Neurol Neurosurg 2013;115(9):1575-1582.

21.Benjamin LA, Bryer A, Emsley HC, Khoo S, Solomon T, Connor MD. HIV infection and stroke: current perspectives and future directions. Lancet Neurol 2012;11(10):878-890.

22.Benjamin LA, Corbett EL, Connor MD, et al. HIV, antiretroviral treatment, hypertension, and stroke in Malawian adults: A case-control study. Neurology 2016;86(4):324-333.

23.Gutierrez J, Albuquerque ALA, Falzon L. HIV infection as vascular risk: A systematic review of the literature and meta-analysis. PLoS One 2017;12(5):e0176686.

24.Cowan LT, Alonso A, Pankow JS, et al. Hospitalized Infection as a Trigger for Acute Ischemic Stroke: The Atherosclerosis Risk in Communities Study. Stroke 2016;47(6):1612-1617.

25.Miller EC, Elkind MS. Infection and Stroke: an Update on Recent Progress. Curr Neurol Neurosci Rep 2016;16(1):2.

26.Minassian C, Thomas SL, Smeeth L, Douglas I, Brauer R, Langan SM. Acute Cardiovascular Events after Herpes Zoster: A SelfControlled Case Series Analysis in Vaccinated and Unvaccinated Older Residents of the United States. PLoS Med 2015;12(12):e1001919.

27.Piel FB, Steinberg MH, Rees DC. Sickle Cell Disease. N Engl J Med 2017;376(16):1561-1573.

28.Switzer JA, Hess DC, Nichols FT, Adams RJ. Pathophysiology and treatment of stroke in sickle-cell disease: present and future. Lancet Neurol 2006;5(6):501-512.

29.Tuinenburg A, Mauser-Bunschoten EP, Verhaar MC, Biesma DH, Schutgens RE. Cardiovascular disease in patients with hemophilia. J Thromb Haemost 2009;7(2):247-254.

30.Miller EC, Gatollari HJ, Too G, et al. Risk Factors for Pregnancy-Associated Stroke in Women With Preeclampsia. Stroke 2017;48(7):1752-1759.

31.Cheng YC, Ryan KA, Qadwai SA, et al. Cocaine Use and Risk of Ischemic Stroke in Young Adults. Stroke 2016;47(4):918-922. 